\title{
Prediction of CCNDI amplification using plasma DNA as a prognostic marker in oesophageal squamous cell carcinoma
}

\author{
H Takeshita', D Ichikawa*,', S Komatsu', M Tsujiura', T Kosuga', K Deguchi', H Konishi', R Morimura', \\ A Shiozaki', H Fujiwara', K Okamoto' and E Otsuji' \\ 'Division of Digestive Surgery, Department of Surgery, Kyoto Prefectural University of Medicine, 465 Kajii-cho, Kawaramachihirokoji, Kamigyo-ku, Kyoto \\ 602-8566, Japan
}

BACKGROUND: We aimed to develop a new biomarker to predict cyclin DI (CCNDI) status using plasma DNA in oesophageal squamous cell carcinoma (ESCC) patients.

METHODS: We evaluated the ratio of the CCNDI ( | |q|3) dosage to the dopamine receptor D2 (DRD2; I lq22-23) dosage (C/D ratio) as CCNDI copy number. This study was divided into three steps: ( I) Determination of a cutoff value for the C/D ratio in test scale; (2) Comparison of the C/D ratio in between plasma samples and cancer tissues in ESCC patients showing high plasma C/D ratio; (3) Validation study of the clinical application of the plasma C/D ratio as a diagnostic and prognostic marker, by comparing with clinicopathologic factors in 96 ESCC patients.

RESULTS: The plasma C/D ratio was significantly higher in the ESCC group than the controls $(P=0.0134)$. A high plasma C/D ratio reflected the tumour $C / D$ ratio, and significantly correlated with a poorer prognosis $(P=0.0 / 86)$. Moreover, the high $C / D$ ratio was found to be an independent prognostic factor on multivariate analysis ( $P=0.0266$; hazard ratio 5.988).

CONCLUSION: Prediction of CCNDI amplification using plasma DNA is thought to be a promising prognostic biomarker in ESCC patients.

British Journal of Cancer (2010) I 02, 1378- 1383. doi:I0.1038/sj.bjc.6605657 www.bjcancer.com

Published online 13 April 2010

(c) 2010 Cancer Research UK

Keywords: biomarker; plasma; copy number; cyclin DI; oesophageal cancer

Oesophageal cancer occurs worldwide with a variable geographic distribution, and ranks eighth in order of occurrence and is the sixth leading cause of cancer mortality (Enzinger and Mayer, 2003). Although there are two different kinds of histologic types of oesophageal cancer, squamous cell carcinoma (ESCC) accounts for $\sim 90 \%$ of all oesophageal cancer diagnosed in Asian countries (Hiyama et al, 2007). In spite of the recent advances in diagnostic techniques and perioperative management, patients with ESCC still show extremely poor survival rates even after extended surgery.

Several recent studies have elucidated that certain molecules, such as p53, cyclin D1 (CCND1) and FAS, have important roles in tumourigenesis and the development of the ESCC (Hollstein et al, 1990; Adélaide et al, 1995; Shinozaki et al, 1996; Gratas et al, 1998). However, few molecules have been applied in clinical setting as therapeutic and/or diagnostic biomarkers. Therefore, the significance of detecting a novel biomarker using reasonable molecules should be emphasised.

Among several molecules, gene amplification of CCND1 mapped to the 11 q13 region, which is a key regulator of the G1 phase of the cell cycle, has been defined as one of the most common genetic aberrations in ESCC, and has been shown to correlate with advanced stage and poor prognosis (Jiang et al, 1992; Kyomoto et al, 1997). In contrast, recent reports have shown that tumour released circulating DNA and RNA in plasma-serum samples were

*Correspondence: Dr D Ichikawa; E-mail: ichikawa@koto.kpu-m.ac.jp Received 5 January 2010; revised 15 March 2010; accepted 18 March 20I0; published online 13 April 2010 useful for detecting the tumour-specific abnormalities and monitoring disease status in cancers (Sozzi et al, 2003; Kimura et al, 2006; Skvortsova et al, 2006; Diehl et al, 2008; Schwarzenbach et al, 2009).

Therefore, we hypothesised that the genome status of CCND1 in primary oesophageal cancer could be predictable by a less invasive, blood-based test, which enable to evaluate primary tumour dynamics and predict prognosis and associated clinicopathological factors. To circumvent the influences of plasma DNA quantity and numerical chromosomal aberrations, we particularly calculated the ratio of the dosage of CCND1 to that of the reference gene, dopamine receptor D2 (DRD2) gene mapped to 11q22-23, as an indicator of the CCND1 copy number (CCND1/DRD2: C/D ratio) (Kyomoto et al, 1997).

In this study, we showed whether the plasma C/D ratio is useful to predict tumour CCND1 amplification in preliminary 40 ESCC patients, and examined the diagnostic value of the $\mathrm{C} / \mathrm{D}$ ratio to detect cancers by comparing findings in ESCC patients and healthy volunteer controls. In addition, we validate the prognostic value of the $\mathrm{C} / \mathrm{D}$ ratio by analysing the relationship between the plasma results and clinicopathological factors in 96 consecutive ESCC patients.

\section{MATERIALS AND METHODS}

\section{Patients and samples}

Between October 2007 and April 2009, recent 40 preoperative plasma samples were collected from consecutive patients with 
ESCC, who underwent R0 (no residual tumour after surgery) or R1 (microscopic residual tumour after surgery) esophagectomy at the Kyoto Prefectural University of Medicine, as well as from 19 healthy volunteers. After determination of the cutoff value for the plasma C/D ratio (see the section 'Quantitative analysis for CCND1 using real-time polymerase chain reaction' described below), we divided the 40 patients into two groups, 19 patients with a high plasma $\mathrm{C} / \mathrm{D}$ ratio and 21 with a low plasma $\mathrm{C} / \mathrm{D}$ ratio. Paraffin-embedded oesophageal tumour tissues and adjacent normal oesophageal tissues were collected from the same 19 patients showing the high plasma $\mathrm{C} / \mathrm{D}$ ratio. To obtain additional evidence that the tumour-derived circulating DNA reflect the plasma $C / D$ ratio, the postoperative plasma samples $(20-51$ days after operation) were also collected from eight patients in the high plasma C/D ratio group, who underwent R0 esophagectomy.

Plasma samples were collected from another 56 consecutive ESCC patients and another 21 healthy volunteers for large-scale validation assays. In total, plasma sample were collected from 40 healthy volunteers and 96 consecutive ESCC patients who underwent curative surgery (R0 or R1) between April 2005 and April 2009.

Resected cancer specimens were fixed in buffered formalin and embedded in paraffin for routine pathological examination. Pathological classification of the tumour was determined according to the UICC classification (Sobin and Fleming, 2002).

\section{Preparation and DNA isolation of plasma and tissues samples}

After obtaining informed consent, $7 \mathrm{ml}$ of peripheral blood was obtained from each patient before any surgery, and from healthy volunteer controls. Immediately after collection, the blood samples were subjected to the isolation of cell-free nucleic acids by the three spin protocol (1500 r.p.m. for $30 \mathrm{~min}, 3000$ r.p.m. for $5 \mathrm{~min}$, 4500 r.p.m. for $5 \mathrm{~min}$ ) to prevent cross contamination from cellular nucleic acid (Tomita et al, 2007). After centrifugation, the plasma sample was stored at $-80^{\circ} \mathrm{C}$ until further processing. Cell-free genomic DNA was isolated from $400 \mu \mathrm{l}$ of the serum sample using the QIAamp blood mini kit (Qiagen, Hilden, Germany). The final elution was performed using a $100 \mu \mathrm{l}$ of the AE buffer of the QIAamp blood mini kit.

Paraffin-embedded tissues were sectioned at $5 \mu \mathrm{m}$ thickness after undergoing routine histologic examination. Genomic DNA of cancerous and adjacent noncancerous oesophageal tissues were extracted from the two slices $5 \mu \mathrm{m}$ thick using DEXPAT (TaKaRa, Kyoto, Japan) according to the manufacturer's protocols.

\section{Quantitative analysis for CCND1 using real-time PCR}

We selected the DRD2 gene as a reference gene, because the DRD2 is located on the same chromosome as CCND1, and DRD2 amplification and overexpression in ESCC have never reported in any gene database, such as GenBank, DDBJ and EMBL. Therefore, the CCND1/DRD2 ratio would reflect the CCND1 copy number without influence of absolute DNA concentration and aneuploidy of chromosome 11.

The serum dosage of CCND1 and DRD2 were quantified by DNA-based real-time PCR using Applied Biosystems 7300 RealTime PCR system (Applied Biosystems, Foster City, CA, USA). The PCR mixture was a final volume of $20 \mu \mathrm{l}$ containing $10 \mu \mathrm{l}$ TaqMan Universal PCR Master Mix (Applied Biosystems), $1 \mu \mathrm{l}$ TaqMan Gene Expression Assays and $9 \mu \mathrm{l}$ each DNA samples. TaqMan Gene Expression Assays for CCND1 (Hs03772544_cn) and DRD2 (Hs05266854_cn) were purchased from Applied Biosystems. All PCR reactions were performed with one cycle of $95^{\circ} \mathrm{C}$ for $10 \mathrm{~min}$, followed by PCR amplification with 40 cycles of $95^{\circ} \mathrm{C}$ for $15 \mathrm{~s}$ and $60{ }^{\circ} \mathrm{C}$ for $60 \mathrm{~s}$.
The CCND1 copy number of DNA samples was determined by the ratio of the CCND1 dosage to the DRD2 dosage (C/D ratio), using the comparative threshold cycle method.

\section{Statistical analysis}

The difference in the plasma $C / D$ ratio between the ESCC and healthy volunteer control groups was assessed using the Mann-Whitney $U$-test, and that between preoperative and postoperative findings was assessed using Wilcoxon $t$-test. $\chi^{2}$ test, Fisher's exact probability test was used to evaluate the correlations between results of the plasma $\mathrm{C} / \mathrm{D}$ ratio and clinicopathological factors. $P$-values $<0.05$ were considered statistically significant. Moreover, overall survival rate was calculated using Kaplan-Meier method, and the significance of differences was determined by log-rank test. Multivariate stepwise Cox regression model was performed to identify significant contributors that were associated independently with death on univariate analysis; multivariate risk ratios are presented with $95 \%$ confidence intervals.

\section{RESULTS}

\section{Study design to develop a novel genomic biomarker of the plasma}

The study design is summarised in Figure 1A. This study was divided into three steps: (1) Determination of a cutoff value of the C/D ratio by comparing results of both plasma from 40 ESCC patients and 19 healthy volunteers; (2) Evaluation whether plasma C/D ratio could monitor tumour dynamics; (3) Validation study for clinical application as a diagnostic and prognostic marker, using the plasma C/D ratio, by comparing the plasma results with clinicopathologic factors in 96 ESCC patients.

\section{Test scale for detection cutoff value of plasma CCND1/DRD2 ratio}

Plasma C/D ratio of 40 ESCC patients and 19 healthy volunteer controls was examined by real-time PCR to determine the cutoff value. Figure $1 \mathrm{~B}$ shows the distribution of the plasma $\mathrm{C} / \mathrm{D}$ ratio in ESCC patients and in the control groups. The plasma C/D ratio was significantly higher in the ESCC patients group than control group (median: 1.23 (range 0.19-7.32) vs median: 1.05 (range 0.39-1.79), $P=0.0134$ ). Consequently, we determined a cutoff value of 1.33 for the plasma $\mathrm{C} / \mathrm{D}$ ratio based on the mean value + s.d. in healthy volunteer controls to distinguish the high $\mathrm{C} / \mathrm{D}$ ratio patients from those with low ratio patients. As a result, 19 patients were categorised into high plasma C/D ratio group, whereas 21 patients in low plasma $\mathrm{C} / \mathrm{D}$ ratio group.

\section{Evaluation whether plasma CCND1/DRD2 ratio could monitor tumour dynamics}

We analysed the C/D ratio of oesophageal cancer and adjacent normal oesophageal tissues in 19 ESCC patients showing a high plasma C/D ratio. The higher C/D ratio of oesophageal tumour compared with that of normal tissues was found in 14 of the 19 patients $(74 \%)$ (Table 1$)$, while a higher C/D ratio of oesophageal tumour was found in only 6 of the 21 ESCC patients showing a low plasma C/D ratio (Supplementary Table 1). These findings indicated that the high plasma $\mathrm{C} / \mathrm{D}$ ratio reflects the amplification in tumour. Moreover, we examined the CCND1 assay in postoperative plasma of eight patients showing high plasma $\mathrm{C} / \mathrm{D}$ ratio in preoperative plasma. The $\mathrm{C} / \mathrm{D}$ ratio reduced significantly in the postoperative plasma samples $(P=0.0357$; Figure $1 C)$. In one patient, the re-elevation of plasma $\mathrm{C} / \mathrm{D}$ ratio was found at 
A

1. Test-scale to determine a cut-off value of the plasma CCND1/DRD2 ratio

Examination of plasma CCND1/DRD2 ratio in 40 ESCC patients and 19 healthy volunteers 2. Evaluation whether plasma CCND1/DRD2 ratio could
monitor tumour dynamics

Comparison of the CCND1/DRD2 ratio between plasma samples and tumour tissue

Comparison of plasma CCND1/DRD2 ratio between pre-operation and post-operation in patients with ESCC

3. Large-scale for validation in the clinical application of the plasma CCND1/DRD2 ratio

Plasma samples from consecutive 96 ESCC patients were analysed

The receiver-operating characteristic (ROC) curve for the plasma CCND1/DRD2 ratio analysis

Evaluation of associated clinicopathological factors and prognostic value

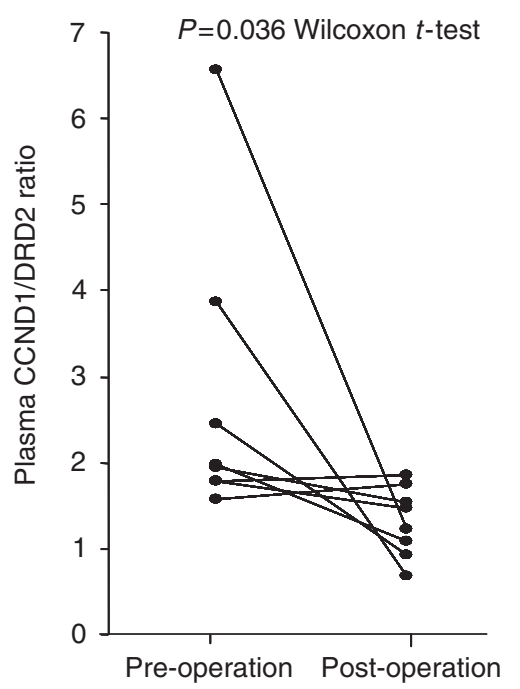

B

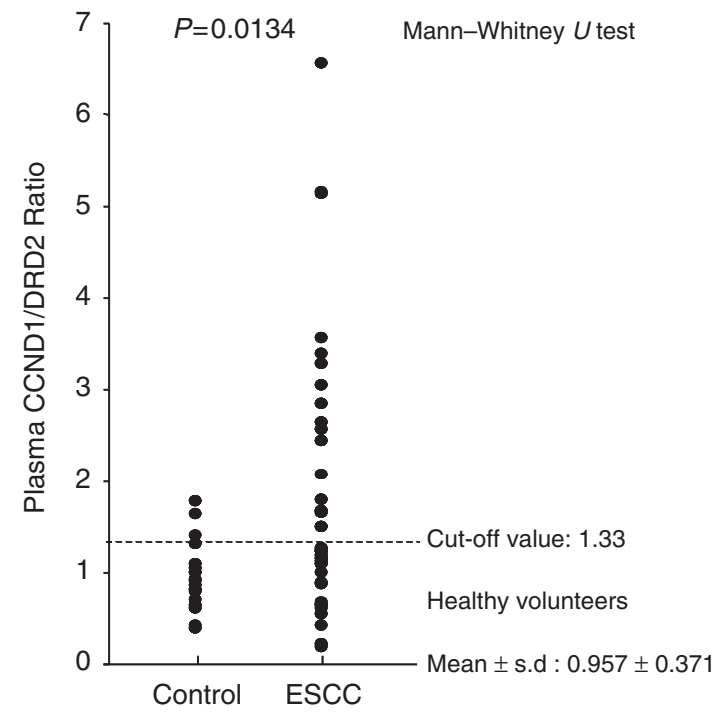

D
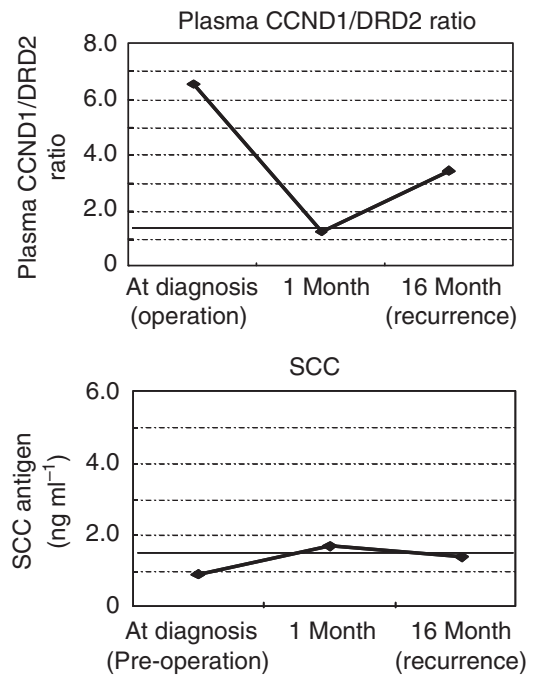

Figure I Study design and initial results to develop a novel genomic biomarker of the plasma. (A) Strategy to identify novel plasma potential biomarker in ESCC. (B) Comparison of plasma CCNDI/DRD2 (C/D) ratio in 40 ESCC patients and 19 healthy volunteers by real-time PCR. The plasma CCNDI/DRD2 ratio was significantly higher in the ESCC group (median: 1.24, range: 0.19-6.56) than in the control group (median: I.05, range: 0.39-1.79). (C) Comparison of plasma CCNDI/DRD2 ratio between pre- and postoperative plasma. The plasma CCNDI/DRD2 ratio was also examined postoperatively in eight patients showing a high plasma CCNDI/DRD2 ratio in preoperative plasma, and the value was significantly reduced in postoperative plasma ( $P=0.0357$, Wilcoxon $t$-test). (D) Changes of the plasma CCNDI/DRD2 ratio and SCC antigen in one patient who developed recurrences. The top and bottom graphs represent the value of the plasma CCNDI/DRD2 ratio and SCC antigen level, respectively. The dotted lines represent the upper limit of each marker: I.33 for plasma CCNDI/DRD2 ratio and $1.5 \mathrm{ng} \mathrm{ml}^{-1}$ for SCC antigen. The patients underwent esophagectomy, however, radiologic examination showed multiple recurrences, lymph nodes and lungs, 12 months postoperatively. The plasma CCNDI/DRD2 ratio re-elevated at the time of diagnosis of recurrences.

Table I Evaluation of tumour CCNDI amplification in high plasma CCNDI/DRD2 ratio group

\section{Tumour CCNDI}

\section{Number Amplification Non-amplification}

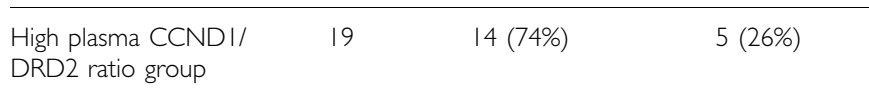

Abbreviations: CCNDI = cyclin DI; DRD2 = dopamine receptor D2.

16 month after surgery, who developed recurrence without elevation of conventional serum tumour marker such as squamous cell carcinoma antigen (SCC) (Figure 1D).

\section{Large scale for validation in the clinical application as a diagnostic and prognostic biomarker}

In total, 96 consecutive patients were included in this study; the mean age of patients was 64.2 years (range: 44-82), the male-female ratio was $3.4: 1$, and 9 with TNM stage 0,23 with stage I, 35 with stage II, 21 with stage III and 8 with stage IV. The mean follow-up period was 13.8 months (range: $0-40$ ). Figure 2 shows the receiver-operating characteristic curves for plasma C/D ratio analysis, and the area under the curve was 0.728 . Sensitivity was $43.7 \%$ (42 out of 96 ) and specificity was $87.5 \%$ (35 out of 40 ) (Supplementary Figure 1).

Correlations between plasma C/D ratio and clinicopathological factors in 96 ESCC patients are summarised in Table 2. The 


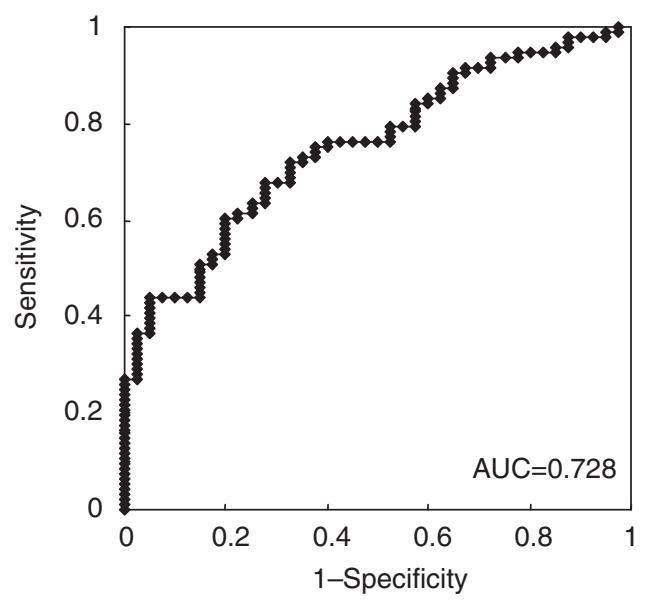

Figure 2 The receiver-operating characteristic (ROC) curves for the plasma CCNDI/DRD2 ratio analysis in 96 ESCC patients and 40 healthy volunteers. The area under the curve (AUC) was 0.728 in 96 ESCC patients vs 40 healthy volunteers.

patients showing high plasma $\mathrm{C} / \mathrm{D}$ ratio tended to have lymph node metastasis although the difference was not significant. There was no significant correlation between the plasma C/D ratio and other clinicopathological factors in this study.

We additionally validated the plasma $\mathrm{C} / \mathrm{D}$ ratio as a prognostic value in 96 ESCC patients. Patients in the high plasma C/D ratio group showed significantly poorer survival than those in the low ratio group (3-year survival rates: 59.4 vs $86.1 \%, P=0.0186$ ) (Figure 3). Univariate analysis showed that the T-stage was also a significant prognostic factor. Both the plasma C/D ratio $(P=0.0266$ hazard ratio 5.988 (range: $1.232-29.411))$ and T-stage were found to be independent prognostic factors on multivariate analysis (Table 3 ).

\section{DISCUSSION}

A noninvasive assay using circulating nucleic acids opens up a new and interesting field in the screening and monitoring of cancer patients. Several investigators have recently reported that the detections of tumour-derived circulating DNA and RNA would be promising diagnostic and prognostic tools in clinical practise (Johnson and Lo, 2002; Fleischhacker and Schmidt, 2007). A majority of these approaches, however, require complicated processing including certain modifications. Furthermore, strict handling is required in cases of mRNA assays.

However, gene amplification is one of the most frequent genomic aberrations involved in the pathogenesis of various cancers. Especially in ESCC, oncogenes, such as SMYD2 (1q32.3q41), EGFR (7p12), MYC (8q24.21), CCND1 (11q13), cIAP1 (11q22) and ERBB2 (17q21.1), have already been identified as major amplification targets associated with development, progression and metastasis of aggressive disease ( $\mathrm{Lu}$ et al, 1988; Imoto et al, 2001; Jain et al, 2007; Komatsu et al, 2009; Sato-Kuwabara et al, 2009). Among them, CCND1 is the gene most frequently amplified $(22-65 \%)$ with high copy numbers, and also associated with a poorer survival outcome in ESCC patients (Lam, 2000). These findings prompted us to detect the CCND1 amplification in plasma samples of ESCC patients, as well as to examine the clinical usefulness of the noninvasive assay as a possible biomarker.

To circumvent the aneuploidy of chromosomes, we first developed real-time quantitative PCR with a reference gene mapped to the same chromosome, and subsequently showed that the ratio, CCND1 (11q13) / DRD2 (11q22-23), in plasma DNA is a valuable
Table 2 Correlation between clinicopathological factors and the plasma CCNDI/DRD2 ratio in consecutive 96 patients with ESCC

\begin{tabular}{|c|c|c|c|c|}
\hline \multirow[b]{2}{*}{ Variable } & \multirow[b]{2}{*}{$n$} & \multicolumn{2}{|c|}{ Plasma CCNDI amplification value } & \multirow[b]{2}{*}{$P$-value ${ }^{b}$} \\
\hline & & Low & High & \\
\hline Total & 96 & $54(56.3 \%)$ & $42(43.7 \%)$ & \\
\hline \multicolumn{5}{|l|}{ Sex } \\
\hline Male & 74 & $44(59.5 \%)$ & $30(40.5 \%)$ & \multirow[t]{2}{*}{0.2450} \\
\hline Female & 22 & $10(45.5 \%)$ & $12(54.5 \%)$ & \\
\hline \multicolumn{5}{|l|}{ Age } \\
\hline$<65$ & 42 & $24(57.1 \%)$ & $18(42.9 \%)$ & \multirow[t]{2}{*}{0.8764} \\
\hline $65 \leqq$ & 54 & $30(55.6 \%)$ & $24(44.4 \%)$ & \\
\hline \multicolumn{5}{|c|}{ Lymphatic invasion } \\
\hline Negative & 67 & $40(59.7 \%)$ & $27(40.3 \%)$ & \multirow[t]{2}{*}{0.3001} \\
\hline Positive & 29 & $14(48.3 \%)$ & $15(51.7 \%)$ & \\
\hline \multicolumn{5}{|c|}{ Venous invasion } \\
\hline Negative & 58 & $30(51.7 \%)$ & $28(48.3 \%)$ & \multirow[t]{2}{*}{0.2694} \\
\hline Positive & 38 & $24(63.2 \%)$ & $14(36.8 \%)$ & \\
\hline \multicolumn{5}{|l|}{$T$ stage $^{\mathrm{a}}$} \\
\hline $\mathrm{TO} / \mathrm{I} / 2$ & 57 & 33 (57.9\%) & $24(42.1 \%)$ & \multirow[t]{2}{*}{0.6945} \\
\hline $\mathrm{T} 3 / 4$ & 39 & $21(53.8 \%)$ & $18(46.2 \%)$ & \\
\hline \multicolumn{5}{|l|}{$N$ stage $^{\mathrm{a}}$} \\
\hline NO & 54 & $35(64.8 \%)$ & $19(35.2 \%)$ & \multirow[t]{2}{*}{0.0550} \\
\hline $\mathrm{NI}$ & 42 & $19(45.2 \%)$ & $23(54.8 \%)$ & \\
\hline \multicolumn{5}{|l|}{ Stage $\mathrm{a}^{\mathrm{a}}$} \\
\hline $0-11$ & 67 & $39(58.2 \%)$ & $28(41.8 \%)$ & \multirow[t]{2}{*}{0.5564} \\
\hline III-IV & 29 & $15(51.7 \%)$ & $14(48.3 \%)$ & \\
\hline \multicolumn{5}{|l|}{ Recurrence } \\
\hline Negative & 72 & 44 (61.1\%) & 28 (38.9\%) & \multirow[t]{2}{*}{0.0963} \\
\hline Positive & 24 & $10(41.7 \%)$ & 14 (58.3\%) & \\
\hline
\end{tabular}

Abbreviations: CCNDI = cyclin DI; ESCC = oesophageal squamous cell carcinoma; DRD2 $=$ dopamine receptor D2. ${ }^{\mathrm{a}} \mathrm{TNM}$ classification. ${ }^{\mathrm{b}}$-values are from $\chi^{2}$ or Fisher's exact probability test and were statistically significant at 0.05 .

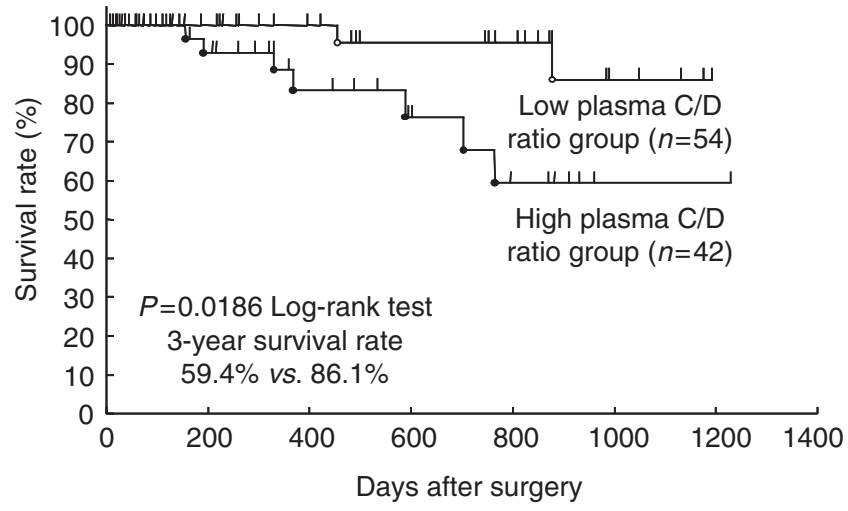

Figure 3 Comparison survival curves according to plasma CCNDI/ DRD2 (C/D) ratio in 96 consecutive patients with ESCC. Patients with a high plasma C/D ratio $(I .33 \leqslant)$ showed significantly poorer survival than those with low ratio $(P=0.0186)$

diagnostic tool for detecting cancers, monitoring therapeutic effects and predicting both clinicopathological factors and postoperative prognosis of ESCC patients. We analysed whether the plasma C/D ratio could monitor tumour dynamics by two different analyses in advance. One is the comparison between the plasma $\mathrm{C} / \mathrm{D}$ ratio and amplification in tumour, which showed that the 
Table 3 Cox proportional hazard regression analysis for overall survival in 96 patients with ESCC

\begin{tabular}{|c|c|c|c|c|}
\hline \multirow[b]{2}{*}{ Factor } & \multirow{2}{*}{$\begin{array}{c}\text { Univariate }^{\mathrm{a}} \\
P \text {-value }\end{array}$} & \multicolumn{3}{|c|}{ Multivariate $^{b}$} \\
\hline & & HR & $95 \% \mathrm{Cl}$ & $P$-value \\
\hline \multicolumn{5}{|l|}{ Sex } \\
\hline Male vs female & 0.8596 & & - & \\
\hline \multicolumn{5}{|l|}{ Age } \\
\hline$<65$ vs $65 \leqq$ & 0.6148 & & - & \\
\hline \multicolumn{5}{|l|}{ Lymphatic invasion } \\
\hline Negative vs positive & 0.7233 & & - & \\
\hline \multicolumn{5}{|l|}{ Venous invasion } \\
\hline Negative vs positive & 0.1472 & & - & \\
\hline \multicolumn{5}{|l|}{$T$ stage } \\
\hline TO/I/2 vs T3/4 & 0.0430 & 4.274 & $|.055-| 7.24 \mid$ & 0.0419 \\
\hline \multicolumn{5}{|l|}{ N stage } \\
\hline No vs NI & 0.6650 & & - & \\
\hline \multicolumn{5}{|l|}{ Plasma CCND I/DRD2 ratio } \\
\hline$<1.33$ vs $1.33 \leqq$ & 0.0186 & 5.988 & $1.232-29.41 \mid$ & 0.0266 \\
\hline
\end{tabular}

Abbreviations: $C C N D I=$ cyclin $\mathrm{DI} ; \mathrm{Cl}=$ confidence interval; $\mathrm{DRD} 2=$ dopamine receptor D2; ESCC = oesophageal squamous cell carcinoma; $H R=$ hazard ratio. aKaplan-Meier method, and the significance of difference was determined by log-rank test. 'Multivariate survival analysis was performed using Cox's proportional hazard model. Statistically significant values are in bold face type.

tumour C/D ratio was high compared with that of adjacent normal tissue in most patients with a high plasma $\mathrm{C} / \mathrm{D}$ ratio. The reasons for the discrepancies in some patients remain to be identified; however, one possible explanation for this finding is the heterogeneity of the primary tumours. Another analysis involves comparison of the plasma C/D ratio in paired plasma obtained before and after surgery. As a result, the plasma C/D ratio was significantly reduced postoperatively in patients who underwent R0 esophagectomy, suggesting that tumour-derived circulating DNA reflect the plasma C/D ratio.

The plasma copy number assay presented in this study has several possibilities for clinical application. First is the screening method in the high-risk group of patients. This assay could detect an elevated C/D ratio regardless of disease stage (detection rate; stage 0 - II vs III-IV: 42.8 vs $48.2 \%$ ) and tumour depth (T0-T2 vs T3-4: 42.1 vs $46.2 \%$ ). These findings suggest that the tumour could release a significant amount of genomic DNA into systemic circulation even at an early stage, and also copy number gains (10-100 copy) derived from CCND1 amplification of each cancer cell chromosome is drastic. This phenomenon was reported in other studies as well as our previous studies showing that the concentration of plasma DNA in cancer patients was significantly higher than that in controls, regardless of tumour stage (Sai et al, 2007; Tomita et al, 2007). Therefore, circulating DNA in peripheral blood may be an early event in the carcinogenesis of solid cancers, and allow the monitoring tumour dynamics as well as prediction of both associated clinicopathological factors and the prognosis at an early stage.

The second possibility is the clinical application as a marker to monitor therapeutic efficacy (Figure 1C) and recurrence as a complement to conventional serum tumour markers, such as SCC and CEA. In this study, the plasma C/D ratio decreased to the normal range after surgery and increased again at recurrence without any change in conventional serum tumour markers (Figure 1D). In addition, the most interesting finding to be emphasised was that this assay could also be useful for predicting patients with poor prognoses. This is the first plasma-serum copy number study to predict the prognosis in cancer patients, although the copy number of the amplified genes in plasma or serum has been evaluated in some previous studies (Chiang et al, 1999; Gotoh et al, 2005; Park et al, 2009).

Other benefits of this assay include the savings of time and effort compared with those required for other plasma-serum assays. TaqMan real-time PCR assay allows us to easily evaluate the copy numbers of plasma amplified genes in a couple of hours. Previously, we reported that methylation-specific PCR (MSP) assays using circulating DNA could be combined to serve as a tumour marker in gastric cancer (Ichikawa et al, 2004; Koike et al, 2004). We also showed that the quantification of circulating mRNA such as hTERT and MUC1 using RT-PCR would be useful for the early detection of primary and recurrent gastric cancers (Tani et al, 2007). However, these assays are time-consuming, and required strict conditions and handlings. Besides, the detection rates of MSP and quantitative mRNA assays are relatively low (15-30\%). Our present plasma copy number assay is more suitable for clinical application from the perspective technical simplicity, rapidity and reliability.

We present here a framework to assess tumour characteristics by noninvasive plasma assay. Recent advances in molecular technologies have allowed the analysis of numerous gene and chromosomal aberrations within the entire genome. In the near future, we could design a 'tailor-made biomarker' assay, based on exhaustive evaluation of genes amplifications in primary tumours. This strategy is currently under evaluation.

In conclusion, this study clearly showed that plasma-based CCND1 copy number provides a valuable biomarker for monitoring treatment efficacy and predicting both the associated clinical factors and prognosis of ESCC. This technology could facilitate clinical decision making and be applicable to tailor-made medicine for each individual.

Supplementary Information accompanies the paper on British Journal of Cancer website (http://www.nature.com/bjc)

\section{REFERENCES}

Adélaide J, Monges G, Dérdérian C, Seitz JF, Birnbaum D (1995) Oesophageal cancer and amplification of the human cyclin $\mathrm{D}$ gene CCND1/PRAD1. Br J Cancer 71: 64-68

Chiang PW, Beer DG, Wei WL, Orringer MB, Kurnit DM (1999) Detection of erbB-2 amplifications in tumors and sera from esophageal carcinoma patients. Clin Cancer Res 5: 1381-1386

Diehl F, Schmidt K, Choti MA, Romans K, Goodman S, Li M, Thornton K, Agrawal N, Sokoll L, Szabo SA, Kinzler KW, Vogelstein B, Diaz Jr LA (2008) Circulating mutant DNA to assess tumor dynamics. Nat Med 14: 985-990

Enzinger PC, Mayer RJ (2003) Esophageal cancer. N Engl J Med 349: $2241-2252$

Fleischhacker M, Schmidt B (2007) Circulating nucleic acids (CNAs) and cancer-a survey. Biochim Biophys Acta 1775: 181-232

Gotoh T, Hosoi H, Iehara T, Kuwahara Y, Osone S, Tsuchiya K, Ohira M, Nakagawara A, Kuroda H, Sugimoto T (2005) Prediction of MYCN amplification in neuroblastoma using serum DNA and real-time quantitative polymerase chain reaction. J Clin Oncol 23: $5205-5210$

Gratas C, Tohma Y, Barnas C, Taniere P, Hainaut P, Ohgaki H (1998) Up-regulation of Fas (APO-1/CD95) ligand and down-regulation of Fas expression in human esophageal cancer. Cancer Res 58: 2057-2062

Hiyama T, Yoshihara M, Tanaka S, Chayama K (2007) Genetic polymorphisms and esophageal cancer risk. Int J Cancer 121: 1643-1658 
Hollstein MC, Metcalf RA, Welsh JA, Montesano R, Harris CC (1990) Frequent mutation of the p53 gene in human esophageal cancer. Proc Natl Acad Sci USA 87: 9958-9961

Ichikawa D, Koike H, Ikoma H, Ikoma D, Tani N, Otsuji E, Kitamura K, Yamagishi H (2004) Detection of aberrant methylation as a tumor marker in serum of patients with gastric cancer. Anticancer Res 24: $2477-2481$

Imoto I, Yang ZQ, Pimkhaokham A, Tsuda H, Shimada Y, Imamura M, Ohki M, Inazawa J (2001) Identification of cIAP1 as a candidate target gene within an amplicon at $11 \mathrm{q} 22$ in esophageal squamous cell carcinomas. Cancer Res 61: 6629-6634

Jain M, Kumar S, Upadhyay R, Lal P, Tiwari A, Ghoshal UC, Mittal B (2007) Influence of apoptosis (BCL2, FAS), cell cycle (CCND1) and growth factor (EGF, EGFR) genetic polymorphisms on survival outcome: an exploratory study in squamous cell esophageal cancer. Cancer Biol Ther 6: $1553-1558$

Jiang W, Kahn SM, Tomita N, Zhang YJ, Lu SH, Weinstein IB (1992) Amplification and expression of the human cyclin D gene in esophageal cancer. Cancer Res 52: 2980-2983

Johnson PJ, Lo YM (2002) Plasma nucleic acids in the diagnosis and management of malignant disease. Clin Chem 48: 1186-1193

Kimura H, Kasahara K, Kawaishi M, Kunitoh H, Tamura T, Holloway B, Nishio K (2006) Detection of epidermal growth factor receptor mutations in serum as a predictor of the response to gefitinib in patients with non-small-cell lung cancer. Clin Cancer Res 12: 3915-3921

Koike H, Ichikawa D, Ikoma H, Otsuji E, Kitamura K, Yamagishi H (2004) Comparison of methylation-specific polymerase chain reaction (MSP) with reverse transcriptase-polymerase chain reaction (RT-PCR) in peripheral blood of gastric cancer patients. J Surg Oncol 87: 182-186

Komatsu S, Imoto I, Tsuda H, Kozaki KI, Muramatsu T, Shimada Y, Aiko S, Yoshizumi Y, Ichikawa D, Otsuji E, Inazawa J (2009) Overexpression of SMYD2 relates to tumor cell proliferation and malignant outcome of esophageal squamous cell carcinoma. Carcinogenesis 30: 1139-1146

Kyomoto R, Kumazawa H, Toda Y, Sakaida N, Okamura A, Iwanaga M, Shintaku M, Yamashita T, Hiai H, Fukumoto M (1997) Cyclin-D1-gene amplification is a more potent prognostic factor than its protein overexpression in human head-and-neck squamous-cell carcinoma. Int $J$ Cancer 74: $576-581$

Lam AK (2000) Molecular biology of esophageal squamous cell carcinoma. Crit Rev Oncol Hematol 33: $71-90$
Lu SH, Hsieh LL, Luo FC, Weinstein IB (1988) Amplification of the EGF receptor and c-myc genes in human esophageal cancers. Int J Cancer 42: $502-505$

Park KU, Lee HE, Park do J, Jung EJ, Song J, Kim HH, Choe G, Kim WH, Lee HS (2009) MYC quantitation in cell-free plasma DNA by real-time PCR for gastric cancer diagnosis. Clin Chem Lab Med 47: $530-536$

Sai S, Ichikawa D, Tomita H, Ikoma D, Tani N, Ikoma H, Kikuchi S, Fujiwara H, Ueda Y, Otsuji E (2007) Quantification of plasma cell-free DNA in patients with gastric cancer. Anticancer Res 27: 2747-2751

Sato-Kuwabara Y, Neves JI, Fregnani JH, Sallum RA, Soares FA (2009) Evaluation of gene amplification and protein expression of HER-2/neu in esophageal squamous cell carcinoma using fluorescence in situ hybridization (FISH) and immunohistochemistry. BMC Cancer 9: 6

Schwarzenbach H, Alix-Panabières C, Müller I, Letang N, Vendrell JP, Rebillard X, Pantel K (2009) Cell-free tumor DNA in blood plasma as a marker for circulating tumor cells in prostate cancer. Clin Cancer Res 15: $1032-1038$

Shinozaki H, Ozawa S, Ando N, Tsuruta H, Terada M, Ueda M, Kitajima M (1996) Cyclin D1 amplification as a new predictive classification for squamous cell carcinoma of the esophagus, adding gene information. Clin Cancer Res 2: $1155-1161$

Skvortsova TE, Rykova EY, Tamkovich SN, Bryzgunova OE, Starikov AV, Kuznetsova NP, Vlassov VV, Laktionov PP (2006) Cell-free and cellbound circulating DNA in breast tumours: DNA quantification and analysis of tumour-related gene methylation. Br J Cancer 94: 1492 - 1495

Sobin LH, Fleming ID (2002) TNM Classification of Malignant Tumors. 6th edn. Wiley-Liss: New York

Sozzi G, Conte D, Leon M, Ciricione R, Roz L, Ratcliffe C, Roz E, Cirenei N, Bellomi M, Pelosi G, Pierotti MA, Pastorino U (2003) Quantification of free circulating DNA as a diagnostic marker in lung cancer. J Clin Oncol 21: $3902-3908$

Tani N, Ichikawa D, Ikoma D, Tomita H, Sai S, Ikoma H, Okamoto K, Ochiai T, Ueda Y, Otsuji E, Yamagishi H, Miura N, Shiota G (2007) Circulating cell-free mRNA in plasma as a tumor marker for patients with primary and recurrent gastric cancer. Anticancer Res 27: $1207-1212$

Tomita H, Ichikawa D, Ikoma D, Sai S, Tani N, Ikoma H, Fujiwara H, Kikuchi S, Okamoto K, Ochiai T, Otsuji E (2007) Quantification of circulating plasma DNA fragments as tumor markers in patients with esophageal cancer. Anticancer Res 27: 2737-2741 